\title{
Psychological Well-Being and Coping in Mothers of Youths With Autism, Down Syndrome, or Fragile X Syndrome
}

\author{
Leonard Abbeduto, Marsha Mailick Seltzer, and Paul Shattuck \\ University of Wisconsin-Madison
}

Marty Wyngaarden Krauss

Brandeis University

Gael Orsmond

Boston University

Melissa M. Murphy

University of Wisconsin-Madison

\begin{abstract}
The psychological well-being of mothers raising a child with a developmental disability varies with the nature of the disability. Most research, however, has been focused on Down syndrome and autism. We added mothers whose adolescent or young adult son or daughter has fragile $\mathrm{X}$ syndrome. The sample was comprised of mothers of a child with fragile $\mathrm{X}$ syndrome $(n=22)$, Down syndrome $(n=39)$, or autism $(n=174)$. Mothers of individuals with fragile $\mathrm{X}$ syndrome displayed lower levels of well-being than those of individuals with Down syndrome, but higher levels than mothers of individuals with autism, although group differences varied somewhat across different dimensions of well-being. The most consistent predictor of maternal outcomes was the adolescent or young adult's behavioral symptoms.
\end{abstract}

Parents raising a child with a developmental disability face challenges that are not shared by parents of typically developing children (Stoneman, 1997). There is, however, substantial evidence that the challenges parents face and the ways in which they deal with these challenges vary with the nature of the child's disability (Dunst, Trivette, \& Cross, 1986; Gallagher, Beckman, \& Cross, 1983; Walker, Van Slyke, \& Newbrough, 1992). This evidence comes primarily from studies of two groups of parents: those having a child with Down syndrome and those having a child with autism (Stoneman, 1997). In the present study, we added a third group: parents whose son or daughter has fragile $\mathrm{X}$ syndrome. This latter group has seldom been studied from the perspective of parental psychological well-being, and its inclusion yields additional insights about the impact of developmental disabilities on parents. We examined group differences in parental psychological well-being and coping, their association with characteristics of the family and characteristics and behavior of the son or daughter, and the potential buffering effects of coping. In doing so, we focused on mothers because, despite changing gender roles, mothers still tend to have primary responsibility for child care and are, thus, most subject to the challenges associated with their child's disability (Gray \& Holden, 1992). In addition, we focused on mothers whose son or 
daughter was an adolescent or young adult (ages 10 to 23) because this is a time of transition and new challenges for families as well as being a period in which behavioral differences between persons with Down syndrome, autism, and fragile $\mathrm{X}$ syndrome may become more pronounced.

It is important to make explicit why parental psychological well-being would be expected to differ as a function of the son or daughter's diagnosis. Certainly, there is nothing inherent in any particular diagnosis that would in and of itself elicit a particular set of parental reactions. Instead, it is likely that the physical and behavioral challenges posed by the child will be critical, and to the extent that those challenges vary across diagnoses, differences in parental reactions are possible. In the case of syndromes that have a genetic origin, we might also expect different parental reactions if the parental genes that are the origin of the child's condition also affect the parent's own characteristics, behaviors, and vulnerability to the challenges of parenting in different ways across syndromes. Finally, we could expect different parental reactions across diagnoses to the extent that those diagnoses are correlated with variations in social acceptance of, and support for, children with special needs and their families. These points have been demonstrated empirically by Cahill and Glidden (1996), who found that differences in parental functioning according to child diagnoses were minimized when the groups were matched on various child characteristics. The implication is that demonstrating that parents of children with different diagnostic conditions are themselves different on measures of parental psychological well-being is merely a first step, with the source of those differences still to be determined. In the present study, we were interested in first determining whether there are differences in maternal psychological well-being across the three groups of mothers and in beginning to understand the sources of those differences among mothers.

Previous research on the impact of a child's disability on parental psychological well-being has demonstrated that mothers of children with Down syndrome often fare better than do mothers of children with other forms of mental retardation. Compared to mothers of children who, as a group, are heterogeneous with respect to etiology, mothers of children with Down syndrome report lower levels of stress (Kasari \& Sigman, 1997; Marcovitch, Goldberg, MacGregor, \& Lojk- asek, 1986), have more extensive and more satisfying networks of support (Hauser-Cram, Warfield, Shonkoff, \& Krauss, 2001; Shonkoff, Hauser-Cram, Krauss, \& Upshur, 1992), and perceive their children to have less difficult temperaments (Kasari \& Sigman, 1997). Parents of children with Down syndrome also report less pessimism about their children's future than do parents of children with either Williams or Smith-Magenis syndrome (Fidler, Hodapp, \& Dykens, 2000), they report fewer family problems than do parents of children with Smith-Magenis syndrome (Fidler et al., 2000), and they are less likely to interpret child noncompliance negatively compared to mothers of children who, as a group, are heterogeneous with respect to etiology (Ly \& Hodapp, 2002). Although the vast majority of studies have focused on young children, there is evidence that the "advantage" of having a son or daughter with Down syndrome continues throughout life (Seltzer, Krauss, \& Tsunematsu, 1993). However, not all researchers have found Down syndrome to be associated with higher levels of psychological wellbeing in mothers compared to other forms of mental retardation (Gath \& Gumley, 1986; Hanson \& Hanline, 1990; Ryde-Brandt, 1991), suggesting that the extent to which Down syndrome is perceived as less stressful will depend on the nature of the comparison group.

In contrast to mothers of children with Down syndrome, mothers of individuals with autism report greater stress, lower levels of social support, and less positive views of their child than do mothers of individuals with mental retardation who, as a group, are heterogeneous in terms of etiology (Donovan, 1988). This result emerges across variations in geographical region and culture, child age, and child IQ (Koegel et al., 1992). Moreover, direct comparisons between mothers of children with Down syndrome and mothers of children with autism are quite consistent in suggesting that mothers of children with Down syndrome experience lower levels of stress (Holroyd \& McArthur, 1976; Kasari \& Sigman, 1997) and have more positive views of their children's characteristics (Kasari \& Sigman, 1997).

These differences in psychological well-being between mothers of children with autism and those with Down syndrome can be traced, in part, to variations in the uncertainty attending the two diagnoses. The long history of research on Down syndrome and the certainty surrounding its diagnosis and cause provide parents with a clear and

(C) American Association on Mental Retardation 
coherent explanation of their child's condition and with a reasonable expectation of what the future holds, hence, fewer worries about the future (Beavers, Hampson, Hulgus, \& Beavers, 1986; Fidler, Hodapp, \& Dykens, 2002). In addition, the fact that the diagnosis of Down syndrome is made so soon after birth allows parents to begin the process of adaptation to their child's condition when their children are only a few hours old. In contrast, the diagnosis of autism is often substantially delayed relative to the onset of parental recognition of developmental problems (Lord \& Rissi, 2000). Moreover, this diagnosis is made on strictly behavioral grounds rather than through a definitive genetic test as in the case of Down syndrome, which may leave many parents wondering whether the diagnosis of autism is "correct" (Lord $\&$ Rissi, 2000). In addition, the life course manifestation of autism has only recently been studied, resulting in parents greater uncertainty about the future compared to parents of individuals with Down syndrome (Seltzer, Krauss, Orsmond, \& Vestal, 2000).

The differences in psychological well-being between mothers of children with autism and mothers of children with Down syndrome may also be due to variations in the children's characteristics and behavior, with autism being associated with fewer positive and more negative behavioral propensities. Thus, the sociability that characterizes Down syndrome (Kasari \& Bauminger, 1998) is, by definition, not characteristic of individuals with autism. Individuals with autism also display more maladaptive behaviors than do persons with Down syndrome (Pueschel, 1996; Seltzer et al., 2000), and these behaviors may interfere with the parent-child relationship. In fact, the rate of child maladaptive behavior is a predictor of parental psychological well-being (Fidler et al., 2000; Friedrich, Wilturner, \& Cohen, 1985; Hodapp, Dykens, \& Masino, 1997; Hodapp, Fidler, \& Smith, 1998). Moreover, in contrast to Down syndrome, individuals with autism display features such as impulsivity, hyperactivity, irritability, and aggressiveness (Diagnostic and Statistical Manual-IV-DSM-IV, American Psychiatric Association, 1994), which are characterized by unpredictability and volatility. The predictability of child maladaptive behavior has been found to be an important determinant of stress and coping in parents, with less predictability associated with higher levels of stress, greater reliance on emotionfocused rather than problem-focused coping, and higher rates of depressive symptomatology in parents (Seltzer, Greenberg, \& Krauss, 1995). Even the physical appearance that is characteristic of individuals with Down syndrome, which is perceived as highly child-like, elicits positive emotional responses from mothers and other adults (Fidler \& Hodapp, 1999).

The challenges faced by mothers of individuals with autism also extend beyond those arising from the degree of certainty attending the child's condition or his or her particular characteristics and behaviors. In particular, there is evidence of an increased risk of a host of problems in other family members, including siblings and parents, with this risk being reflective of the broader autism phenotype (Piven, 2001). Thus, there is a higher recurrence risk for siblings of children with autism compared to the general population (Jorde et al., 1991; Piven et al., 1990), and the rates of cognitive, linguistic, and social impairments and psychiatric disturbances are greater in siblings of affected individuals than in siblings of individuals with Down syndrome (August, Stewart, \& Tsai, 1981; Bolton et al., 1994; Piven et al., 1990). Further, parents of children with autism display elevated rates (compared to the general population) of social impairments and personality characteristics known to lead to social impairments (Piven, Palmer, Jacobi, Childress, \& Arndt, 1997; Piven, Palmer, Landa et al., 1997), psychiatric disturbances (DeLong, 1994; Delong \& Nohria, 1994; Lainhart \& Folstein, 1994), learning disabilities (Bolton et al., 1994; Folstein \& Rutter, 1977; Piven et al., 1990), and deficits in communication (Landa, Folstein, \& Isaacs, 1991). In short, mothers of persons with autism may not only face greater challenges from their child's condition, they may also be less equipped to deal with those challenges than are mothers of individuals with Down syndrome (Seltzer et al., 2000), who, as a group, are not at increased risk of psychiatric, language, or cognitive symptoms. Mothers of individuals with autism may also face the challenge of raising multiple children with special needs.

Fragile $\mathrm{X}$ syndrome is second only to Down syndrome as a genetic cause of mental retardation, affecting 1 in 4,000 males and 1 in 8,000 females (Dykens, Hodapp, \& Finucane, 2000). The impact of raising a child with fragile $\mathrm{X}$ syndrome on parents has been investigated in only a single published study (Franke et al., 1996). Nevertheless, there are reasons to believe that mothers of children with fragile $\mathrm{X}$ syndrome, like mothers of per- 
sons with autism, may face greater parenting challenges than do those of individuals with Down syndrome. Similar to parents of children with autism, parents often do not receive the diagnosis of fragile $\mathrm{X}$ syndrome until long after developmental delays have been of concern (Carmichael, Pembrey, Turner, \& Barnicoat, 1999), which is stressful for parents (Roy, Johnsen, Breese, \& Hagerman, 1995). Bailey, Skinner, Hatton, and Roberts (2000) found that parents did not receive a diagnosis of fragile $\mathrm{X}$ syndrome until their child was near the age of 3 years, more than a year after the child had been diagnosed with a developmental delay. Receipt of the fragile $\mathrm{X}$ syndrome diagnosis is even later in the cohort of families whose children are adolescents or young adults today (Poehlmann, Clements, Farsad, Abbeduto, \& Murphy, 2003). Parents of individuals with fragile $X$ syndrome may have little help in resolving their uncertainty because knowledgeable and effective professional supports are currently less extensive and effective for families affected by the syndrome than for other developmental disorders, including Down syndrome and autism (York, von Fraunhofer, \& Sedgwick, 1999).

Psychological well-being in mothers of individuals with fragile $\mathrm{X}$ syndrome might also be threatened because sons and daughters with the syndrome, like those with autism, display relatively high rates of maladaptive behaviors (Hagerman, 1999; Keysor \& Mazzocco, 2002), such as hyperactivity and social anxiety, which often isolates them from others. In fact, a substantial number of individuals with fragile $\mathrm{X}$ syndrome meet diagnostic criteria for autism, and those who do not often display autistic-like behaviors (Dykens \& Volkmar, 1997; Feinstein \& Reiss, 2001). Such behaviors are seen in both males and females, although on average they are more frequent and severe in males (Mazzocco, 2000). Moreover, parents anecdotally report that their sons and daughters with fragile $\mathrm{X}$ syndrome go through alternating periods of "calm" and "storm," the latter being characterized by anxiety-related behaviors, tantrums, and aggressive outbursts. As noted previously for autism, such unpredictability may be a source of substantial stress for parents.

As is the case in autism, the challenges faced by mothers of individuals with fragile $\mathrm{X}$ syndrome extend beyond the affected child. In particular, the mothers of children with fragile $\mathrm{X}$ syndrome are themselves carriers of either the full mutation or premutation of the fragile $\mathrm{X}$ gene (Hagerman,
1999), which may have phenotypic effects and, thus, affect their ability to deal with parenting challenges. Many women who carry the full mutation have mental retardation, and those who have normal-range IQs often have impairments in executive functions, discourse comprehension, and math ability (Mazzocco, 2000; Simon, Keenan, Pennington, Taylor, \& Hagerman, 2001). Women with the full mutation also display increased rates of social anxiety, schizotypal symptoms (e.g., illogical reasoning, odd perceptual experiences), and autistic-like behaviors compared to IQ matches (Feinstein \& Reiss, 2001; Mazzocco, Kates, Baumgardner, Freund, \& Reiss, 1997; Sobesky, Porter, Pennington, \& Hagerman, 1995). The finding of elevated rates of depression in women with the full mutation, however, are inconsistent (Sobesky, Pennington, Porter, Hull, \& Hagerman, 1994). Although there has been limited research on women who carry the premutation (Keyser \& Mazzocco, 2002), there is some evidence of elevated rates of affective disorders (Franke et al., 1996; Hagerman \& Hagerman, 2002), but no consistent evidence of cognitive effects has been obtained to date (Hagerman \& Hagerman, 2000; Simon et al., 2001; Sobesky et al., 1995). In addition, because the syndrome is inherited, many mothers are raising more than one affected child (Hagerman, 1999), which may lead to greater challenges compared to mothers caring for only one child with special needs.

Taken together, the foregoing observations suggest that the challenges faced by mothers of children with fragile $\mathrm{X}$ syndrome should be more similar to those of mothers raising children with autism than those of mothers raising children with Down syndrome. In fact, Franke et al. (1996) found no difference in the rates of clinically diagnosed affective disorders between mothers of children with fragile $\mathrm{X}$ syndrome and mothers of children with autism, although both groups were characterized by higher rates than seen in the general population. It is possible, however, that differences in psychological well-being between these two groups of mothers might emerge on measures of problems that are at subclinical levels but are, nonetheless, serious enough to interfere with individual and family functioning. Moreover, Franke et al. did not examine maternal psychological well-being in relation to child behaviors and characteristics. This makes it impossible to distinguish between those aspects of maternal functioning resulting from the challenges of parenting an af- 
fected child and those resulting from maternal genetic status. More generally, although there have been numerous studies of socioemotional functioning in women with either the full mutation or the premutation, little is known about the impact on psychological well-being of parenting a son or daughter with fragile $\mathrm{X}$ syndrome.

In examining differences in psychological well-being between mothers of children with different types of developmental disabilities, it is important to recognize that the challenges facing mothers may change at different stages of the family life cycle. The period of adolescence and young adulthood may be especially challenging for parents because of the impending transition from school to work and a heightened concern about their son or daughter's future (Lueckling \& Fabian, 1997). In fact, there is evidence of a decrease in parental psychological well-being with increased age of the child, from childhood through adolescence (Seltzer et al., 2000; Stoneman, 1997) among families of children with mental retardation (Wikler, 1986) or autism (Fong, Wilgosh, \& Sobsey, 1993).

In adolescence, there are differences in the developmental trajectories for Down syndrome, autism, and fragile $\mathrm{X}$ syndrome that may create very different levels and types of challenges for mothers. In particular, persons with fragile $\mathrm{X}$ syndrome display age-related declines in their rate of development in both cognitive and adaptive skills during adolescence (Dykens et al., 2000). In contrast, persons with Down syndrome display gains in social skills during this period relative to persons with mental retardation of unknown or heterogeneous etiology or persons with motor impairments (Hauser-Cram et al., 2001). The problem behaviors of persons with autism often intensify during adolescence and further challenge their parents (Seltzer et al., 2000). Such differences in the developmental trajectories of affected offspring during adolescence and young adulthood may require different adaptations and, thus, also contribute to differentiation of mothers of individuals with fragile $\mathrm{X}$ syndrome, autism, and Down syndrome.

In summary, the present study was designed to examine the psychological well-being and coping of mothers caring for an adolescent or young adult with Down syndrome, fragile $\mathrm{X}$ syndrome, or autism. We focused on those dimensions of maternal psychological well-being that in previous research have been shown to be sensitive to dif- ferences in the nature of the son or daughter's disability. In particular, we examined maternal feelings of pessimism about their son or daughter's future, views on the quality of their relationship with their son or daughter, and self-reported depressive symptomatology. We hypothesized that of the three groups of mothers, those parenting an adolescent or young adult with Down syndrome would report the least pessimism about their son or daughter's future, the greatest feelings of closeness in their relationship with the son or daughter, and the lowest rate of depressive symptoms. We also predicted that mothers of adolescents and young adults with Down syndrome would report the greatest use of problem-focused coping and the lowest use of emotion-focused coping, the former generally seen as more effective in buffering mothers from parenting challenges than the latter (Seltzer et al., 1995). We also expected that the mothers of adolescents and young adults with fragile $\mathrm{X}$ syndrome would be more similar to mothers of individuals with autism than to mothers of individuals with Down syndrome, although more precise predictions were not possible due to the lack of research on parenting and fragile $\mathrm{X}$ syndrome. We examined the factors that predicted maternal psychological wellbeing, including the behavioral symptoms of the adolescent or young adult, with the aim of explaining diagnosis-related differences among mothers. We also examined the possibility that coping strategies would moderate the effects of the son or daughter's behavioral problems on maternal psychological well-being.

\section{Method}

The present analysis was based on two ongoing studies of families of individuals with developmental disabilities, one focused on families of individuals with either fragile $\mathrm{X}$ or Down syndrome and the other on families of individuals with autism. As there was considerable overlap across studies in the age range of the individuals with disabilities and a common core of measures completed by their mothers, it was possible to conduct the present comparative analysis. The differing goals of these projects required different sample sizes and, therefore, the number of mothers available for inclusion in the present analyses was substantially greater for the autism group $(n$ $=174)$ than for the fragile $\mathrm{X}$ syndrome $(n=22)$ or Down syndrome group $(n=39)$. 


\section{Sample}

Recruitment. Mothers of participants with Down syndrome or fragile $\mathrm{X}$ syndrome were recruited through advertisements in newspapers throughout Wisconsin, Iowa, and Illinois; newsletters distributed by regional and national professional organizations; university-based research registries of families having a child with a disability; and brochures mailed to special educators and genetics clinics in the region. Because of its lower prevalence, participants with fragile $\mathrm{X}$ syndrome were recruited nationally, whereas those with Down syndrome lived in Wisconsin and surrounding states. The families of the participants with autism were recruited in Wisconsin and Massachusetts through agencies, schools, diagnostic clinics, postings on the Internet, mailing lists and registries of families having a son or daughter with a disability maintained by the investigators' university research center, and via the media.

Confirmation of the diagnosis. The parents of all participants with Down syndrome reported etiology as being trisomy 21 . We were able to obtain reports confirming the karyotype for most participants with Down syndrome. Reports of DNA confirmation of the fragile $\mathrm{X}$ full mutation were available for all but 2 of the participants with fragile X syndrome, with only cytogenetic confirmation available for them. All participants with fragile $\mathrm{X}$ syndrome had the full mutation, although cases of mosaicism (i.e., premutation plus full mutation) were included.

Mothers of participants with fragile X syndrome were asked to provide the results of any genetic testing that had been conducted to determine their status as carriers of the fragile $\mathrm{X}$ premutation or full mutation. However, less than half of the women responding reported having had genetic testing, and many of those did not have copies of the results. Of those who had the results, only one mother had undergone DNA testing. We were unable, therefore, to consider maternal pre- full-mutation carrier status.

Unlike Down syndrome or fragile X syndrome, in which laboratory genetic testing is used diagnostically, the diagnosis of autism is based on behavioral criteria. All participants in the autism sample met two criteria: (a) they had to have received a diagnosis on the autism spectrum (Autistic Disorder; Asperger's Disorder; or Pervasive Developmental Disorder, Not Otherwise SpecifiedPDD-NOS) from a medical, psychological, or ed- ucational professional and (b) their Autism Diagnostic Interview-Revised (Lord, Rutter, \& LeCouter, 1994) lifetime algorithm profile had to be consistent with their reported autism spectrum disorder diagnosis.

A standard short form of the Autism Diagnostic Interview-Revised (C. Lord, personal communication, February 1999), consisting of the 37 items that comprise the diagnostic algorithm of this instrument, was administered by appropriately trained interviewers to confirm that all participants met the current diagnostic criteria for autism spectrum disorders. The Autism Diagnostic Interview-Revised is a standardized face-to-face interview conducted with a primary caregiver that is based on the DSM-IV and International Classification of Diseases-ICD-10 (World Health Organization, 1990) criteria for autism. In the present autism sample, 164 of the 174 of the individuals met all of the Autism Diagnostic Interview-Revised criteria for Autistic Disorder. The profiles of the remaining 10 cases were reviewed and found to be consistent with their autism spectrum disorder diagnosis (i.e., PDD-NOS or Asperger's).

Exclusionary criteria. None of the adolescents or young adults with Down syndrome or fragile $\mathrm{X}$ syndrome in the present sample had autism. The autism status of participants in these groups was confirmed by first asking the mother, father, and teacher of each target adolescent and young adult to complete the Autism Behavior Checklist (Krug, Arick, \& Almond, 1980). This checklist (which is described in more detail below) is a commonly used screening measure in which the informant is asked to indicate which of the common behavioral manifestations of autism the target individual displays. Following Volkmar et al. (1988), we used a score of 44 or higher as reflecting the possible appropriateness of an autism diagnosis. Any participant who met or exceeded this score according to the responses of at least two of the three informants was then referred for clinical evaluation by a licensed psychologist at a developmental disabilities clinic. The psychologist then evaluated the participant against DSM-IV criteria for autistic spectrum disorder. Note that informants seldom disagreed in their Autism Behavior Checklist scoring (e.g., only 10\% of all mother and teacher pairs differed in terms of whether the target individuals exceeded the threshold score of 44, with no consistent pattern with regard to which of the two informants reported higher scores). 
None of the mothers of the target adolescents and young adults in the present autism sample reported that their child had Down syndrome, fragile X syndrome, Rett's Disorder, Childhood Disintegrative Disorder, or tuberous sclerosis. These co-morbid conditions were excluded because of the distinct developmental trajectories characteristic of each of them.

Thus, the participants in the present study consisted of three nonoverlapping diagnostic groups. Other criteria for inclusion in this analysis were that the mother had to be the biological parent of the child with the disability and, to decrease the number of factors to consider in the analyses, the mother had to be currently married.

Characteristics of the participants. Table 1 presents the characteristics of the participants. The mothers averaged in age from the mid- to late 40s, with the mothers of individuals with Down syndrome significantly older than the other two groups of mothers. This difference would be expected in light of the fact that the risk of having a child with Down syndrome is known to increase with maternal age. Family income averaged between $\$ 50,000$ and $\$ 60,000$ and more than two thirds of the mothers in each group were employed outside the home, with no diagnostic group differences in family income or maternal employment status. Approximately half of the mothers had graduated from college or had an advanced degree, with no difference across diagnostic groups. The families of individuals with Down syndrome were larger in size than were the families in the other two groups $(3.4$ children per family in the group with Down syndrome versus just under 3 children for the other two groups). The families who had a son or daughter with fragile X syndrome, however, had significantly more children with a disability per family than did families in the other two groups.

In the fragile $\mathrm{X}$ syndrome sample, there were several families with more than one child with the full mutation and a disability. In such cases, we selected as the target adolescent or young adult the one who was between the ages of 10 and 23 years. If more than one child qualified, the target was selected at random. In the Down syndrome and autism cases, no family had more than one child with Down syndrome or autism who fell into the age range of interest, although some families in these two groups had additional children with those disabilities outside of the age range of interest.

(C) American Association on Mental Retardation
The age of the target adolescents and young adults averaged near 16 years, with a range of 10 to 23 years in each of the diagnostic groups. All targeted individuals lived at home with their parents. There were more males among the adolescents and young adults with autism than among those with Down syndrome. As expected, the three groups also differed with respect to their total scores on the Autism Behavior Checklist (described subsequently), which provided a measure of problem behaviors, particularly those reflective of the symptoms of autism. Those who had autism scored substantially higher than those with fragile $\mathrm{X}$ syndrome, with those with Down syndrome having the lowest scores.

\section{Measures}

Mothers in the three groups all completed measures of their psychological well-being, which formed the dependent variables; coping; and the Autism Behavior Checklist, which provided an assessment of their son or daughter's problem behaviors and competence in several domains that have been shown previously (e.g., Kasari \& Sigman, 1997) to be sources of stress for parents.

Maternal depressive symptoms were assessed by the Center for Epidemiologic Studies Depression Scale-hereafter called the Depression Scale (Radloff, 1977). The scale consists of 20 items in which the frequency of depressive symptoms during the preceding week is rated on a 4-point scale ranging from 0 (rarely) to 3 (most of the time). A score of 16 or higher indicates the risk of clinical depression. Alpha reliability for this instrument was .90 for the present sample.

Pessimism felt about the individual with disabilities was measured using the 11-item Pessimism subscale of the Questionnaire on Resources and Stress (QRS-F; Friedrich, Greenberg, \& Crnic, 1983). According to Friedrich et al., "the central characteristic of this subscale is an immediate and future pessimism about the child's prospects of achieving self-sufficiency" (p. 44). Mothers indicate their agreement (coded 1) or disagreement (coded 0 ) with the items, which are summed, with higher scores indicating a greater degree of pessimism. Alpha reliability for the sample was .72.

Closeness of the mother-child relationship was measured by the Positive Affect Index (Bengtson \& Black, 1973). In this 10 -item scale, the first 5 items assess the level of understanding, trust, fairness, respect, and affection that the mother feels toward her son or daughter with the disability, 


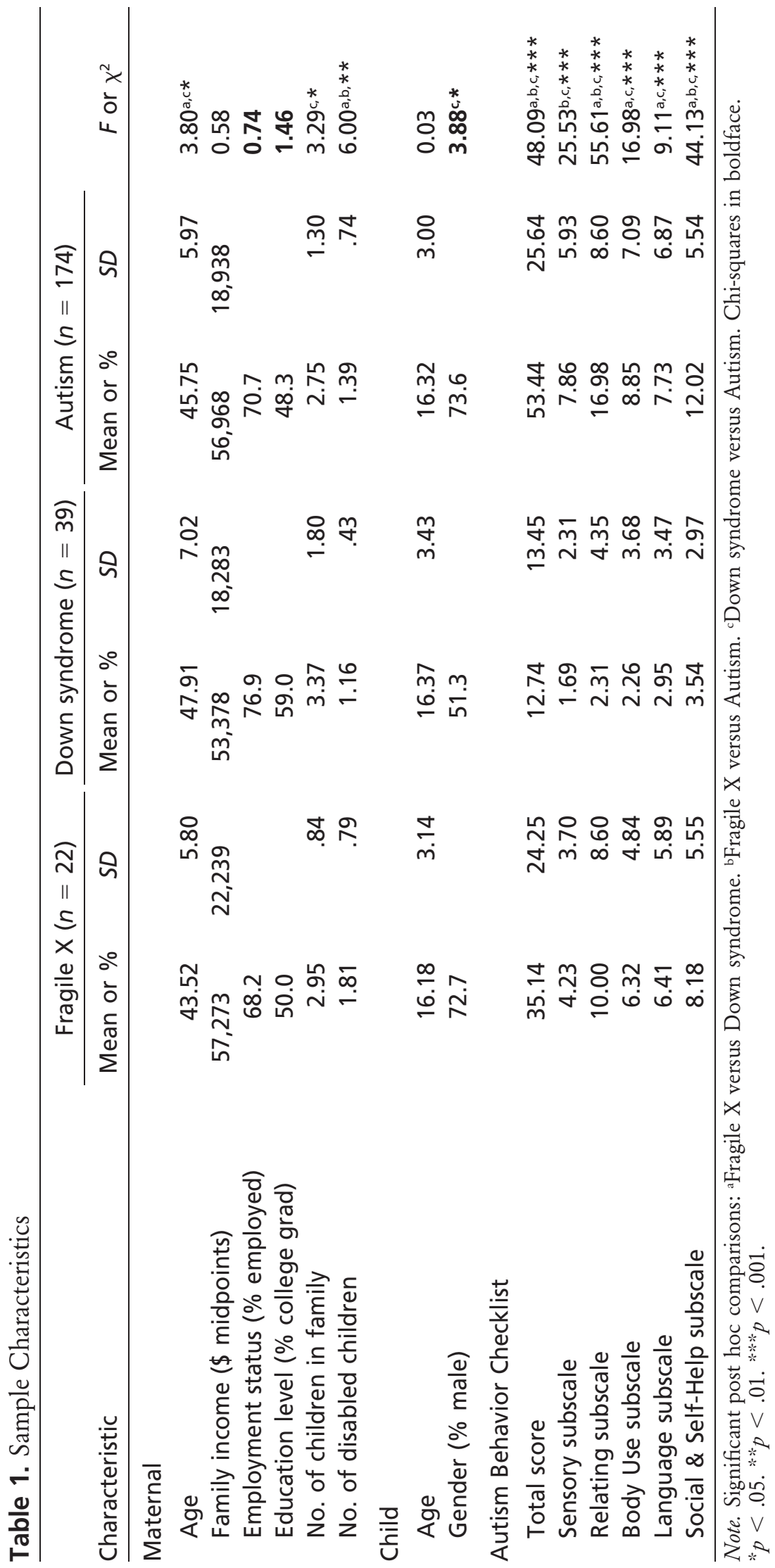


whereas the next 5 items assess the mother's perception of reciprocated closeness (i.e., the extent to which the son or daughter is understanding, trusting, etc., of the mother). Each item is rated on a 6-point scale, with higher scores indicting a better relationship quality. Alpha reliability for the mother's rating of closeness toward her child was .78 for our sample, and for reciprocated closeness perceived by the mother, it was .83 .

Coping refers to the ways in which people respond to stressful events. Coping was measured with Carver, Scheier, and Weintraub's (1989) Multidimensional Coping Inventory, which consists of 13 four-item subscales. Each item is rated in terms of how often $(1=$ not at all to $4=a$ lot $)$ the respondent uses a particular coping strategy when experiencing a difficult or stressful event. We chose the eight subscales representing theoretical aspects of problem- or emotion-focused coping (Pearlin \& Schooler, 1978). Four subscales measured problem-focused coping: active coping refers to direct attempts to remove, circumvent, or reduce the effects of a stressor; planning involves planning an action to deal with a stressor; suppression of competing activities refers to putting other things aside to focus on the stressful situation; and positive reinterpretation and growth involves reframing a problematic event in a positive light (Carver et al., 1989). Four other subscales measured emotion-focused coping: denial involves denying that a stressor exists or is real; focusing on and venting of emotions is the focusing on the stressor and ventilating those feelings; behavioral disengagement involves the reduction of efforts to deal with a stressor; and mental disengagement involves turning to thoughts and activities to take one's mind off of the problem (Carver et al., 1989). Alpha reliability for the present sample was .89 for problem-focused coping and .74 for emotion-focused coping.

The behavioral symptoms manifested by the target adolescent or young adult were indexed by maternal ratings on the 57-item Autism Behavior Checklist. The items on this checklist are differentially weighted to reflect the centrality of the problem behavior to the diagnosis of autism. The items are also grouped into five subscales: Sensory (displays of nonresponsiveness or heightened responsiveness to sensory stimuli); Relating (failures to engage with or react to other people); Body and Object Use (stereotyped body movements, preference for routines, and self-injury); Language (failures to achieve typical developmental mile- stones in language and the use of language in socially inappropriate ways); and Social and SelfHelp (failures in acquiring adaptive behaviors as well as destructive and aggressive behavior). We focused on autism spectrum behaviors rather than other types of behavioral problems (e.g., anxiety, depression) because the former were expected to maximally distinguish the three groups of adolescents and young adults and to be highly salient for mothers. Alpha reliability across the 57 items of the Autism Behavior Checklist was .91 for the present sample of mothers.

In analyzing the contribution of behavioral symptoms to maternal psychological well-being, we report those involving only the Autism Behavior Checklist total score. In general, the three groups of adolescents and young adults were distinguished by their scores on each of the subscales, although the participants with fragile $\mathrm{X}$ syndrome did not differ significantly from the group with Down syndrome on the Sensory subscale or from the group with autism on the Body Use and Language subscales (see Table 1). Moreover, the pattern of results for predicting maternal outcomes is similar across the subscales of the Autism Behavior Checklist as well as for individual items focused on particular high-salience maladaptive behaviors (e.g., aggression), important developmental milestones, or indicators of competence (e.g., use of multiword utterances). (The data are available from the authors.) Thus, use of the Autism Behavior Checklist total score provided increased reliability without obscuring the relationships between child behavior and maternal outcome compared to the use of subscales or individual items.

A missing response for an item in any questionnaire was replaced by the participant's mean score across all relevant items for the scale or subscale, with the requirement that no more than $75 \%$ of the items for a scale (or subscale) could have missing values. In the case of missing demographic data (e.g., family income), the diagnostic group mean was substituted for the missing value. Missing values were infrequent, with no more than $4 \%$ of the values being coded as missing for any measure.

\section{Results}

Our first research question concerned differences among the mothers with respect to psychological well-being and coping. This question was 
addressed by conducting a series of one-way ANOVAs for each dependent measure, with Fisher's least significant difference technique (Levin, Serlin, \& Seaman, 1994) used for post hoc comparisons to maintain a family-wise alpha level of $p \leq$ .05 (see Table 2). The three groups of mothers differed with respect to their feelings of pessimism about the adolescent or young adult's future. As hypothesized, mothers of those with Down syndrome were significantly less pessimistic than were mothers in the other two groups.

The groups also differed in their perceptions of the quality of the mother-child relationship. Consistent with our hypothesis, mothers of adolescents and young adults with Down syndrome reported more closeness in the relationship than did mothers of those with autism, but the mothers of those with fragile $\mathrm{X}$ syndrome did not differ from the other two groups. Regarding the mother's perceptions of her child's feelings of reciprocated closeness, the three groups were significantly divergent, with mothers of those with (a) Down syndrome reporting the most perceived reciprocated closeness, (b) autism reporting the least, and (c) fragile $\mathrm{X}$ syndrome in the middle.

The three groups of mothers differed in their level of depressive symptoms, with mothers of adolescents and young adults with autism reporting significantly higher levels of depressive symptoms than did mothers of those with Down syndrome. In contrast, mothers of those with fragile $\mathrm{X}$ syndrome did not differ from the other two groups.
It is important to note that the average Depression Scale score for all three groups was below the cutoff for clinical depression (16); however, a significantly higher proportion of mothers of adolescents and young adults with autism had Depression Scale scores in the clinical range than did the other two groups $(33.3 \%$ of mothers of adolescents and young adults with autism versus $18.2 \%$ of mothers of those with fragile $\mathrm{X}$ syndrome and $10.3 \%$ of mothers of those with Down syndrome, $\chi^{2}(2, N=154)=6.46, p=.01$. Counter to our hypothesis, the three groups of mothers did not differ in their use of either problem-focused or emotion-focused coping.

Next, we asked whether the group differences in maternal pessimism, closeness in the relationship with the son or daughter with the disability, and depressive symptoms could be explained, in part, by differences in demographic characteristics of the family, the behavioral symptoms of the adolescent or young adult, and maternal coping. We focused on family demographic factors because they constitute the social context in which nonnormative parenting is experienced. We focused on the adolescent or young adult's level of behavioral symptoms because such symptoms constitute the immediate challenge of nonnormative parenting and on coping because past research has shown that coping can buffer the effects of behavior problems in mothers of adults with developmental disabilities. We hypothesized that once contextual factors, behavioral symptoms, and ma-

Table 2. Means and SDs of Maternal Psychological Scale Scores

\begin{tabular}{|c|c|c|c|c|c|c|c|}
\hline \multirow[b]{2}{*}{ Scale } & \multicolumn{2}{|c|}{$\begin{array}{l}\text { Fragile } X \\
(n=22)\end{array}$} & \multicolumn{2}{|c|}{$\begin{array}{c}\text { Down } \\
(n=39)\end{array}$} & \multicolumn{2}{|c|}{$\begin{array}{l}\text { Autism } \\
(n=174)\end{array}$} & \multirow[b]{2}{*}{$F$} \\
\hline & Mean & $S D$ & Mean & $S D$ & Mean & $S D$ & \\
\hline Pessimism (QRS) ${ }^{d}$ & 6.05 & 2.38 & 4.82 & 1.92 & 6.65 & 2.34 & $10.38^{a_{1}, c_{1} * * *}$ \\
\hline \multicolumn{8}{|c|}{$\begin{array}{l}\text { Closeness in the mother/adolescent } \\
\text { relationship }\end{array}$} \\
\hline $\begin{array}{l}\text { Maternal rating of } \\
\text { closeness }\end{array}$ & 25.27 & 2.35 & 26.13 & 3.19 & 24.30 & 3.49 & $5.10^{c, * *}$ \\
\hline $\begin{array}{l}\text { Perceived reciprocated } \\
\text { closeness }\end{array}$ & 24.05 & 2.98 & 26.26 & 2.69 & 21.62 & 4.44 & $21.95^{a, b, c, * * *}$ \\
\hline Depressive symptoms & 11.00 & 7.65 & 6.74 & 6.31 & 12.60 & 9.10 & $7.47^{c, * * *}$ \\
\hline Emotion-focused coping & 11.81 & 5.42 & 12.50 & 5.46 & 13.29 & 5.28 & 0.97 \\
\hline Problem-focused coping & 30.09 & 8.82 & 31.95 & 7.82 & 32.33 & 7.34 & 0.86 \\
\hline
\end{tabular}

Note. Significant post hoc comparisons: ${ }^{a}$ Fragile $\mathrm{X}$ vs. Down syndrome. ${ }^{b}$ Fragile $\mathrm{X}$ vs. Autism. ${ }^{\mathrm{c} D o w n}$ syndrome vs. Autism. ${ }^{\mathrm{d}}$ Questionnaire on Resources and Stress.

$* p<.01 .{ }^{* * *} p<.001$. 
ternal coping patterns were controlled, the group differences would become nonsignificant. We also hypothesized that level of behavioral symptoms would be the strongest predictor of maternal outcomes across diagnostic groups. Finally, we hypothesized that coping would buffer the effects of behavioral symptoms on maternal outcomes.

Table 3 presents the findings of the four regression models, one for each of the maternal outcome variables: pessimism, feelings of closeness to son or daughter, perceptions of son or daughter's reciprocated feelings of closeness, and level of depressive symptoms. The findings for each outcome variable are reported in two steps. In Step 1 , two variables representing diagnostic group are the only predictors, whereas in Step 2, variables measuring contextual background characteristics, behavioral symptoms, and maternal coping are added. To the extent that diagnostic group coefficients that were significant in Step 1 became nonsignificant after the other variables were en- tered in Step 2, diagnostic group differences can be explained by contextual, behavioral, or coping factors.

In these regressions, the two variables measuring diagnostic groups were dummy variables indexing whether the child had autism or Down syndrome. By including these two variables in the regression models, each of these diagnostic groups was contrasted with fragile $\mathrm{X}$ syndrome, which was the omitted category (Aiken \& West, 1991). A significant coefficient would signify that the particular group (autism or Down syndrome) differs from those with fragile $\mathrm{X}$ syndrome with respect to the dependent variable.

Regarding maternal pessimism about the future of the son or daughter with the disability, mothers of those with Down syndrome were significantly less pessimistic than mothers of those with fragile $\mathrm{X}$ syndrome (Step 1), but this difference disappeared after all other factors in the model were controlled (Step 2). There was no dif-

Table 3. Multiple Regressions (Standardized Coefficients)

\begin{tabular}{|c|c|c|c|c|}
\hline Variable & Pessimism & $\begin{array}{c}\text { Maternal rating } \\
\text { of relationship } \\
\text { quality }\end{array}$ & $\begin{array}{l}\text { Reciprocated } \\
\text { relationship } \\
\text { quality }\end{array}$ & $\begin{array}{c}\text { Depression } \\
\text { Scale }\end{array}$ \\
\hline \multicolumn{5}{|l|}{ Step 1} \\
\hline Autism vs. Fragile $X$ & .112 & -.125 & $-.240 * *$ & .080 \\
\hline DS ${ }^{a}$ vs. Fragile $X$ & $-.193^{*}$ & .093 & $.186 *$ & -.180 \\
\hline \multicolumn{5}{|l|}{ Step 2} \\
\hline Autism vs. Fragile X & .038 & -.100 & $-.197 *$ & .040 \\
\hline DS vs. Fragile $X$ & -.119 & -.033 & .050 & -.104 \\
\hline \multicolumn{5}{|l|}{ Contextual factors } \\
\hline Family income & -.107 & -.123 & $-.123 *$ & $-.205^{* *}$ \\
\hline Maternal education & $.189 * *$ & -.109 & -.078 & .063 \\
\hline No. of disabled children & .006 & -.090 & -.107 & $.148^{*}$ \\
\hline Gender of target child & .040 & -.029 & -.022 & -.041 \\
\hline Age of child & $.155^{* *}$ & .105 & -.048 & -.038 \\
\hline \multicolumn{5}{|l|}{ Behavioral symptoms } \\
\hline Autism Behavior Checklist score & $.269 * * *$ & $-.241 * *$ & $-.283 * * *$ & $.191 * *$ \\
\hline \multicolumn{5}{|l|}{ Maternal coping } \\
\hline Problem focused coping & $-.216 * * *$ & $.238 * * *$ & $.160 * *$ & $-.134 *$ \\
\hline Emotion focused coping & $.213 * * *$ & $-.134^{*}$ & -.102 & $.345 * * *$ \\
\hline$R^{2}$ (Step 1) & .082 & .042 & .159 & .061 \\
\hline$R^{2}$ (Step 2) & .262 & .197 & .278 & .303 \\
\hline$R^{2}$ change & $.180 * * *$ & $.155^{* * *}$ & $.118 * * *$ & $.243 * * *$ \\
\hline
\end{tabular}

aDown syndrome. ${ }^{*} p<.05 .{ }^{* *} p<.01 .{ }^{* * *} p<.001$. 
ference between those with autism and those with fragile X syndrome at either Step 1 or Step 2. Among the contextual variables, more highly educated mothers and mothers of older sons or daughters were more pessimistic about their child's future. In addition, the number of behavioral symptoms of the adolescent and young adult and the mother's coping were significant predictors. Mothers of adolescents and young adults with more behavioral symptoms were more pessimistic about their son or daughter's future. Further, mothers who used lower levels of problemfocused coping and higher levels of emotion-focused coping tended to have higher pessimism scores than those who manifested the reverse coping profile.

Regarding the mother's rating of closeness, mothers of adolescents and young adults with fragile X syndrome did not differ at either Step 1 or Step 2 from the mothers in either of the other two groups. Contextual factors were not predictive of maternal perception of closeness of the relationship. However, as in the prediction of pessimism, mothers of adolescents and young adults with fewer behavioral symptoms tended to report greater closeness, and mothers who used problemfocused coping and refrained from using emotionfocused coping reported greater closeness.

Regarding the mother's perception of her adolescent's reciprocated feelings of closeness to her, mothers of adolescents and young adults with autism perceived less reciprocated closeness than did mothers of those with fragile $\mathrm{X}$ syndrome (Step 1). This difference remained even after controlling for contextual factors, level of behavioral symptoms, and maternal coping (Step 2). Although there was a difference between mothers of adolescents and young adults with Down syndrome and those with fragile $\mathrm{X}$ syndrome in Step 1, this difference became nonsignificant when other factors were controlled in Step 2. The adolescent's behavioral symptoms again were predictive, with a greater number of symptoms predicting diminished perceived reciprocated closeness. Finally, mothers who used higher levels of problem-focused coping were more likely to perceive reciprocated closeness from the son or daughter.

Regarding the mother's level of depressive symptoms, mothers of adolescents and young adults with fragile $\mathrm{X}$ syndrome did not differ from either of the other two groups. Rather, the family's income, the number of children in the family who had developmental disabilities, the son or daughter's Autism Behavior Checklist score, and the mother's coping style were significant predictors. Mothers tended to be more depressed if there was lower family income, other children with a disability in the family, if the adolescent had a greater number of behavioral symptoms, and if the mother reported less use of problem-focused and greater use of emotion-focused coping.

In follow-up analyses, we examined whether either problem-focused or emotion-focused coping buffered the effects of behavioral symptoms on maternal outcomes. None of the interaction terms (coping by Autism Behavior Checklist score) was significant. We also constructed threeway interactions (coping by Autism Behavior Checklist score by diagnostic group) to assess the possibility of differential coping effects by group, but again, none was significant. Thus, our hypothesis that coping would buffer the stressful effects of behavioral symptoms on maternal outcomes was not supported (results of these analyses are available from the authors).

\section{Discussion}

The results of the present analyses confirm past reports about the family context of individuals with Down syndrome and autism and provide new insights regarding the family context of individuals with fragile $\mathrm{X}$ syndrome. Consistent with past research (Kasari \& Sigman, 1997; Seltzer et al., 1993), we found that mothers of adolescents and young adults with Down syndrome reported low levels of pessimism about their son or daughter's future, a close relationship with their son or daughter, and low levels of depressive symptoms. Also consistent with past research (Holroyd \& McArthur, 1976; Kasari \& Sigman, 1997; Koegel et al., 1992), mothers of adolescents and young adults with autism reported higher levels of pessimism, more distant relationships with the affected son or daughter, and higher levels of depressive symptoms than did the mothers of adolescents and young adults with Down syndrome. Given the clear difference in the extent of problem behaviors reported on the Autism Behavior Checklist for the adolescents and young adults with autism versus those with Down syndrome, it is likely that some of the differences in maternal outcomes were the result of the divergent caregiving challenges posed by these two groups of adolescents and young adults. It is also possible that genetic vulnerability in mothers whose adoles- 
cents and young adults had autism (i.e., the broader autism phenotype; Jorde et al., 1991; Piven et al., 1990) contributed to their elevated levels of depressive symptoms and relationship distance.

How did mothers of adolescents and young adults with fragile $\mathrm{X}$ syndrome compare with the other two groups? They were more pessimistic about their child's future than were mothers of adolescents and young adults with Down syndrome but did not differ in this respect from their counterparts whose adolescents and young adults had autism. This pessimism may reflect not undue concerns and worries but rather a realistic appraisal of the future based on the behavioral challenges that typically accompany fragile $\mathrm{X}$ syndrome (Clayton, Glidden, \& Kiphart, 1994). In any event, these results suggest that these mothers were especially worried about their son or daughter's future. Mothers of adolescents and young adults with fragile $\mathrm{X}$ syndrome also perceived less reciprocated closeness in the relationship with the adolescent or young adult than did mothers of adolescents and young adults with Down syndrome, but did not perceive that this relationship was as distant as did mothers of adolescents and young adults with autism. Further, mothers of adolescents and young adults with fragile $\mathrm{X}$ syndrome did not differ from the other two groups of mothers in either their feelings of closeness with their adolescent or young adult or their level of depressive symptoms. In general, mothers of adolescents and young adults with fragile $X$ syndrome display fewer signs of compromised psychological well-being than do mothers of individuals with autism but more such signs than do mothers of individuals with Down syndrome.

It is interesting to note that the mothers of adolescents and young adults with fragile X syndrome did not differ from the other groups of mothers in depressive symptoms. Some previous researchers have reported higher rates of depression in females who carry the full mutation and, albeit less consistently, even in females who carry the premutation compared to other diagnostic groups (Keysor \& Mazzocco, 2002). In these studies, however, researchers have typically not restricted their samples to women who have affected children. Moreover, previous investigators have often focused on chronic depression in contrast to current or recent displays of the symptoms of depression. These methodological differences may account for the relatively low levels of depressive symptoms reported by the mothers of adolescents and young adults with fragile $\mathrm{X}$ syndrome in the present study. Nevertheless, $16 \%$ of these mothers had levels of depressive symptoms above the cutoff for clinical depression and, thus, the mental health status of these women remains a concern.

Based on previous research (Essex, Seltzer, \& Krauss, 1999; Seltzer et. al., 1995), we had hypothesized that coping would buffer the stressful effects of behavioral symptoms; however, there was no evidence of a buffering effect. It is possible that the small sample size for the fragile $\mathrm{X}$ syndrome and Down syndrome groups strained the statistical power needed to detect coping by group interaction effects. The possibility of Type II error, therefore, should not be discounted. Second, we have argued that an essential ingredient in effective coping is the expectation of gaining some control over the sources of stress as a result of coping (Seltzer et al., 1995). Because the behavioral symptoms of individuals with autism or fragile $\mathrm{X}$ syndrome are often unpredictable, it may be the case that maternal coping efforts are ineffective in changing this source of stress; hence, coping might not have any measurable effects on regulating the psychological well-being of these mothers, even though they may exert coping efforts.

The strongest and most consistent predictor of maternal outcomes was the extent and severity of the behavioral symptoms of the adolescent, as measured by the Autism Behavior Checklist. Higher scores on this measure significantly predicted greater maternal pessimism, less closeness in the relationship between the mother and adolescent or young adult, and greater maternal depressive symptoms. A similar effect of behavioral symptoms across diagnostic groups has been reported by Floyd and Gallagher (1997) and Donenberg and Baker (1993). Indeed, previous research has shown behavior problems to be a better predictor of parenting stress than is IQ (Hodapp et al., 1997). Thus, our research confirms past findings about the effects of behavior problems on parental psychological well-being, while extending the findings to a new diagnostic group (i.e., fragile $\mathrm{X}$ syndrome). It also supports the cautionary note sounded by Cahill and Glidden (1996), who argued that differences in child characteristics must be considered when interpreting group differences in maternal behavior and psychological functioning.

As in previous studies, we found that contextual factors (e.g., maternal education) were also re- 
lated to the measures of maternal well-being (Ryff \& Seltzer, 1996). Of special interest was the finding that the number of children with disabilities in the family was related to maternal symptoms of depression. Inclusion of multiple affected children within the family is one of the features that distinguishes families of children with autism or fragile X syndrome from families of children with Down syndrome and many other forms of mental retardation. This suggests that there is a need in future research to conduct more detailed analyses of the impact on parental well-being of variations in family composition.

It is important to note that despite the powerful effect of child characteristics on maternal outcomes (Cahill \& Glidden, 1996) and the contribution of contextual factors, such as number of affected children, differences between the three groups of mothers could not be explained solely by the behavioral symptoms of the target adolescent or young adult, contextual factors, or variations in maternal coping strategy. In particular, differences in perception of reciprocated motherchild relationship quality between mothers of individuals with fragile $\mathrm{X}$ syndrome and the other groups of mothers remained significant even after controlling for the contribution of these other factors. A task for future researchers is to identify the sources of this unexplained variation in maternal perception of relationship quality. Plausible candidates include differences in maternal genotype and social supports that are correlated with child diagnosis. It will also be important to evaluate a wider range of the behaviors and characteristics that distinguish between adolescents and young adults with Down syndrome, fragile $\mathrm{X}$ syndrome, and autism than was measured in the present study.

Indeed, one limitation of the present study was the somewhat narrow assessment of problem behaviors in the adolescents and young adults, reflecting only autism-spectrum behaviors. Other problem behaviors that are likely to distinguish the groups (e.g., hyperactivity and social anxiety) were not measured and may explain some of the differences among the three groups of mothers or additional variance within each group. Moreover, we did not have comparable measures of competence or level of functioning (e.g., IQ) across the three samples. Although such measures have not been found in previous research to account for substantial variation in maternal psychological outcomes, we cannot rule out a role in the present study.

There are several additional limitations of the present study. First, we lacked an adequate characterization of the genetic status (as pre- or fullmutation carriers) of the mothers of the adolescents and young adults with fragile $\mathrm{X}$ syndrome. Inclusion of genetic status as a predictor in our regressions would have provided a more complete picture of the sources of parenting stress in this group, especially in light of recent findings of correlations between molecular measures and the clinical phenotype, even in women who carry only the premutation (Hagerman \& Hagerman, 2002; Nolin et al., 2003). We plan to pursue this issue in our future research. Nevertheless, it is important that child characteristics, most notably problem behaviors, predicted parenting outcome in mothers of individuals with fragile $\mathrm{X}$ syndrome; hence, it is clear that not all of the psychological risk for these mothers resulted from their genotype. Second, not all of the adolescents and young adults with autism in our sample had undergone genetic testing to rule out fragile $\mathrm{X}$ syndrome. There is evidence suggesting that as many as 5\% of individuals with autism may have fragile $\mathrm{X}$ syndrome (Feinstein \& Reiss, 2001). Future researchers will need to attend more closely to the genetic status of the individual with autism. Finally, we have focused here only on mothers. In future research, it will be important to also study fathers because the factors that affect maternal and paternal well-being may well be distinct (Essex et al., 1999).

The present findings support the notion of differential experiences for family members depending upon the specific diagnosis of their child with a developmental disability. In part, these differences reflect the unique challenges posed by the young people with the diagnoses of interest. Thus, treating these behavioral challenges directly may alleviate some negative outcomes for mothers. It may also be helpful, given the intractable nature of some of these behavioral challenges, to provide parents with respite and other forms of social support that may buffer some of the inevitable stress associated with these behaviors. The present results, however, are also consistent with the notion that some parents have a genetic vulnerability for less than optimal outcomes and that this vulnerability is magnified by the challenges of raising a son or daughter with special needs. Thus, these parents are likely to benefit from on- 
going interventions directed at their own needs, perhaps concentrated at life transitions known to be especially challenging (e.g., the child's transition from high school to the workplace). In summary, information gleaned from further studies involving comparisons of families grappling with different diagnoses can be of help to clinicians and service providers so that they may better tailor their interventions to families' specific needs.

\section{References}

Aiken, L. S., \& West, S. G. (1991). Multiple regression: Testing and interpreting interactions. Newbury Park, CA: Sage.

American Psychiatric Association. (1994). Diagnostic and statistical manual of mental disorders (4th ed.). Washington, DC: Author.

August, G. J., Stewart, M. A., \& Tsai, L. (1981). The incidence of cognitive disabilities in siblings of autistic children. British Journal of Psychiatry, 138, 416-422.

Bailey, D. B., Skinner, D., Hatton, D. D., \& Roberts, J. (2000). Family experiences and factors associated with diagnosis of fragile $\mathrm{X}$ syndrome. Journal of Developmental and Behavioral Pediatrics, 21, 315-321.

Beavers, J., Hampson, R. B., Hulgus, Y. F., \& Beavers, W. R. (1986). Coping in families with a retarded child. Family Process, 25, 365-378.

Bengtson, V. L., \& Black, K. D. (1973, October 16). Solidarity between parents and children: Four perspectives on theory development. Paper presented at the Theory Development Workshop, National Council on Family Relations, Toronto.

Bolton, P., MacDonald, H., Pickles, A., Rios, P., Goode, S., Crowson, M., Bailey, A., \& Rutter, M. (1994). A case-control family study of autism. Journal of Child Psychology and Psychiatry, 35, 877-900.

Cahill, B. M., \& Glidden, L. M. (1996). Influence of child diagnosis on family and parental functioning: Down syndrome versus other disabilities. American Journal on Mental Retardation, 101, 149-160.

Carmichael, B., Pembrey, M., Turner, G., \& Barnicoat, A. (1999). Diagnosis of fragile-X syndrome: The experiences of parents. Journal of Intellectual Disability Research, 43, 47-53.

Carver, C. S., Sheier, M. F., \& Weintraub, J. K. (1989). Assessing coping strategies: A theoret- ically based approach. Journal of Personality and Social Psychology, 56, 267-283.

Clayton, J. M., Glidden, L. M., \& Kiphart, M. J. (1994). The Questionnaires on Resources and Stress: What do they measure? American Journal on Mental Retardation, 99, 313-316.

DeLong, G. R. (1994). Children with autistic spectrum disorder and a family history of affective disorder. Developmental Medicine, 36, 674-687.

DeLong, G. R., \& Nohria, C. (1994). Psychiatric family history and neurological disease in autistic spectrum disorders. Developmental Medicine and Child Neurology, 36, 441-448.

Donenberg, G., \& Baker, B. L. (1993). The impact of young children with externalizing behaviors on their families. Journal of Abnormal Child Psychology, 21, 179-198.

Donovan, A. M. (1988). Family stress and ways of coping with adolescents who have handicaps: Maternal perceptions. American Journal on Mental Retardation, 92, 502-509.

Dunst, C., Trivette, C., \& Cross, A. (1986). Mediating influences of social support: Personal, family, and child outcomes. American Journal of Mental Deficiency, 90, 403-417.

Dykens, E. M., Hodapp, R. M., \& Finucane, B. M. (2000). Genetics and mental retardation syndromes: A new look at behavior and interventions. Baltimore: Brookes.

Dykens, E. M., \& Volkmar, F. R. (1997). Medical conditions associated with autism. In D. J. Cohen \& F. R. Volkmar (Eds.), Handbook of autism and pervasive developmental disorders (2nd ed., pp. 388-407). New York: Wiley.

Essex, E. L., Seltzer, M. M., \& Krauss, M. W. (1999). Differences in coping effectiveness and well-being among aging mothers and fathers of adults with mental retardation. American Journal on Mental Retardation, 104, 545563.

Feinstein, C., \& Reiss, A. L. (2001). Autism: The point of view from fragile $\mathrm{X}$ studies. Journal of Autism and Developmental Disorders, 28, 393-405.

Fidler, D. J., \& Hodapp, R. M. (1999). Craniofacial maturity and perceived personality in children with Down syndrome. American Journal on Mental Retardation, 104, 410-421.

Fidler, D. J., Hodapp, R. M., \& Dykens, E. M. (2000). Stress in families of young children with Down syndrome, Williams syndrome, and Smith-Magenis syndrome. Early Education and Development, 11, 395-406. 
Fidler, D. J., Hodapp, R. M., \& Dykens, E. M. (2002). Behavioral phenotypes and special education: Parent report of educational issues for children with Down syndrome, PraderWilli syndrome and Williams syndrome. Journal of Special Education, 36, 80-88

Floyd, F. J., \& Gallagher, E. M. (1997). Parental stress, care demands, and use of support services for school-age children with disabilities and behavior problems. Family Relations, 46, 359-371.

Folstein, S., \& Rutter, M. (1977). Genetic influences and infantile autism. Nature, 265, 726728.

Fong, L., Wilgosh, L., \& Sobsey, D. (1993). The experience of parenting an adolescent with autism. International Journal of Disability, Development and Education, 40, 105-113.

Franke, P., Maier, W., Hautzinger, M., Weiffenbach, O., Gansicke, M., Iwers, B., Poustka, F., Schwab, S. G., \& Froster, U. (1996). Fragile-X carrier females: Evidence for a distinct psychopathological phenotype? American Journal of Medical Genetics, 64, 334-339.

Friedrich, W. N., Greenberg, M. T., \& Crnic, K. (1983). A short-form of the Questionnaire on Resources and Stress. American Journal of Mental Deficiency, 88, 41-48.

Friedrich, W. N., Wilturner, L. T., \& Cohen, D. S. (1985). Coping resources and parenting mentally retarded children. American Journal of Mental Deficiency, 90, 130-139.

Gallagher, J. J., Beckman, P. J., \& Cross, A. H. (1983). Families of handicapped children: Sources of stress and its amelioration. Exceptional Children, 50, 10-19.

Gath, A., \& Gumley, D. (1986). Family background of children with Down's syndrome and of children with a similar degree of mental retardation. British Journal of Psychiatry, 149, 161-171.

Gray, D. E., \& Holden, W. J. (1992). Psycho-social well-being among parents of children with autism. Australia and Nere Zealand Journal of Developmental Disabilities, 18, 83-93.

Hagerman, R. J. (1999). Neurodevelopmental disorders. Oxford: Oxford University Press.

Hagerman, R. J., \& Hagerman, P. J. (2002). The fragile $\mathrm{X}$ premutation: Into the phenotypic fold. Current Opinion in Genetics and Development, 12, 278-283.

Hanson, M., \& Hanline, M. F. (1990). Parenting a child with a disability: A longitudinal study of parental stress and adaptation. Journal of Early Intervention, 14, 234-248.

Hauser-Cram, P., Warfield, M. E., Shonkoff, J. P., \& Krauss, M. W. (2001). Children with disabilities: A longitudinal study of child development and parent well-being. Monographs of the Society for Research in Child Development, 66, Serial No. 266.

Hodapp, R. M., Dykens, E. M., \& Masino, L. (1997). Families of children with Prader-Willi syndrome: Stress-support and relations to child characteristics. Journal of Autism and Developmental Disorders, 27, 11-24.

Hodapp, R. M., Fidler, D. J., \& Smith, A. C. M. (1998). Stress and coping in families of children with Smith-Magenis syndrome. Journal of Intellectual Disability Research, 5, 331-340.

Holroyd, J., \& McArthur, D. (1976). Mental retardation and stress on the parents: A contrast between Down's syndrome and childhood autism. American Journal on Mental Deficiency, 80, 431-436.

Jorde, L., Hasstedt, S., Ritvo, E., Mason-Brothers, A., Freeman, B. J., Pingree, C., McMahon, W. M., Petersen, B., Jenson, W. R., \& Mo, A. (1991). Complex segregation analysis of autism. American Journal of Human Genetics, 29, 932-938.

Kasari, C., \& Bauminger, N. (1998). Social and emotional development in children with mental retardation. In J. A. Burack, R. M. Hodapp, \& E. Zigler (Eds.), Handbook of mental retardation and development (pp. 411-433). New York: Cambridge University Press.

Kasari, C., \& Sigman, M. (1997). Linking parental perceptions to interactions in young children with autism. Journal of Autism and Developmental Disorders, 27, 39-57.

Keysor, C. S., \& Mazzocco, M. M. M. (2002). A developmental approach to understanding fragile X syndrome in females. Microscopy Research and Technique, 57, 179-186.

Koegel, R. L., Schreibman, L., Loos, L. M., Dirlich-Wilhelm, H., Dunlap, G., Robbins, F. R., \& Pilenis, A. J. (1992). Consistent stress profiles in mothers of children with autism. Journal of Autism and Developmental Disorders, 22, 205-216.

Krug, D. A., Arick, J. R., \& Almond, P. J. (1980). Autism Screening Instrument for Educational Planning. Examiner's manual. Portland, OR: ASIEP Education.

Lainhart, J. E., \& Folstein, S. E. (1994). Affective

(C) American Association on Mental Retardation 
disorders in people with autism: A review of published cases. Journal of Autism and Developmental Disorders, 24, 587-601.

Landa, R., Folstein, S. E., \& Isaacs, C. (1991). Spontaneous narrative-discourse performance of parents of autistic individuals. Journal of Speech and Hearing Research, 34, 1339-1345.

Levin, J. R., Serlin, R. C., \& Seaman, M. A. (1994). A controlled, powerful multiple-comparison strategy for several situations. Psychological Bulletin, 115, 153-159.

Lord, C., \& Rissi, S. (2000). Diagnosis of autism spectrum disorders in young children. In A. M. Wetherby \& B. M. Prizant (Eds.), Autism spectrum disorders: A transactional developmental perspective (pp. 11-30). Baltimore: Brookes.

Lord, C., Rutter, M., \& LeCouter, A. (1994). Autism Diagnostic Interview-Revised: A revised version of a diagnostic interview for caregivers of individuals with possible pervasive developmental disorders. Journal of Autism and Developmental Disorders, 24, 659-685.

Lueckling, R. G., \& Fabian, E. S. (1997). Transition from school to work. In S. M. Pueschel \& M. Sustrova (Eds.), Adolescents with Down syndrome: Toward a more fulfilling life (pp. 235243). Baltimore: Brookes.

Ly, T. M., \& Hodapp, R. M. (2002). Maternal attribution of child noncompliance in children with mental retardation: Down syndrome versus other causes. Journal of Developmental and Behavioral Pediatrics, 23, 322-329.

Marcovitch, S., Goldberg, S., MacGregor, D., \& Lojkasek, M. (1986). Patterns of temperament in three groups of developmentally delayed preschool children: Mother and father ratings. Developmental and Behavioral Pediatrics, 7 , 247-252.

Mazzocco, M. M. M. (2000). Advances in research on the fragile X syndrome. Mental Retardation and Developmental Disabilities Research Reviezes, 6, 96-106.

Mazzocco, M. M. M., Kates, W. R., Baumgardner, T. L., Freund, L. S., \& Reiss, A. L. (1997). Autistic behaviors among girls with fragile $\mathrm{X}$ syndrome. Journal of Autism and Developmental Disorders, 27, 415-435.

Nolin, S. L., Brown, W. T., Glicksman, A., Houck, G. E., Jr., Gargano, A. D., Sullivan, A., Binacalana, V., Brondum-Nielsen, K., Hjalgrim, H., Holinski-Feder, E., Kooy, F., Longshore, J., Macpherson, J., Mandel, J. L., Matthijs, G., Rousseau, F., Steinbach, P., Vais- anen, M. L., von Koskull, H., \& Sherman, S. L. (2003). Expansion of the fragile X CGG repeat in females with premutation or intermediate alleles. American Journal of Medical Genetics, 72, 454-464.

Pearlin, L. I., \& Schooler, C. (1978). The structure of coping. Journal of Health and Social Behavior, 19, 2-21.

Piven, J. (2001). The broad autism phenotype: A complementary strategy for molecular genetic studies of autism. American Journal of Medical Genetics, 105, 34-35.

Piven, J., Gayle, J., Chase, G. A., Fink, B., Landa, R., Wzorek, M., \& Folstein, S. (1990). A family history study of neuropsychiatric disorders in the adult siblings of autistic individuals. Journal of the American Academy of Child and Adolescent Psychiatry, 29, 177-183.

Piven, J., Palmer, P., Jacobi, D., Childress, D., \& Arndt, S. (1997). Broader autism phenotype: Evidence from a family history study of multiple-incidence autism families. American Journal of Psychiatry, 154, 185-190.

Piven, J., Palmer, P., Landa, R., Santengelo, S., Jacobi, D., \& Childress, D. (1997). Personality and language characteristics in parents from multiple-incidence autism families. American Journal of Medical Genetics, 74, 398-411.

Poehlmann, J., Clements, M., Farsad, V., Abbeduto, L., \& Murphy, M. M. (2003). Family experiences and maternal resolution of their child's diagnosis of fragile $X$ syndrome or Down syndrome. Paper presented at the annual Gatlinburg Conference on Research and Theory in Mental Retardation and Developmental Disabilities, Annapolis, MD.

Pueschel, S. M. (1996). Young people with Down syndrome: Transition from childhood to adulthood. Mental Retardation and Developmental Disabilities Research Reviewes, 2, 90-95.

Radloff, L. S. (1977). The CES-D scale: A selfreport depression scale for research in the general population. Applied Psychological Measurement, 1, 385-401.

Roy, J. C., Johnsen, J., Breese, K., \& Hagerman, R. (1995). Fragile X syndrome: What is the impact of diagnosis on families? Developmental Brain Dysfunction, 8, 327-335.

Ryde-Brandt, B. (1991). Defence strategies and anxiety in mothers of disabled children. European Journal of Personality, 5, 367-377.

Ryff, C. D., \& Seltzer, M. M. (1996). The uncharted years of midlife parenting. In C. D. 
Ryff \& M. M. Seltzer (Eds.), The parental experience at midlife (pp. 3-25). Chicago: University of Chicago Press.

Seltzer, M. M., Greenberg, J. S., \& Krauss, M. W. (1995). A comparison of coping strategies of aging mothers of adults with mental illness or mental retardation. Psychology and Aging, 10, 64-75.

Seltzer, M. M., Krauss, M. W., Orsmond, G. I., \& Vestal, C. (2000). Families of adolescents and adults with autism: Uncharted territory. In L. M. Glidden (Ed.), International Review of Research on Mental Retardation (Vol. 23, pp. 267-294). San Diego: Academic Press.

Seltzer, M. M., Krauss, M. W., \& Tsunematsu, N. (1993). Adults with Down syndrome and their aging mothers: Diagnostic group differences. American Journal on Mental Retardation, 97, 464-508.

Shonkoff, J. P., Hauser-Cram, P., Krauss, M. W., \& Upshur, C. (1992). Development of infants with disabilities and their families: Implications for theory and service delivery. Monographs of the Society for Research in Child Development, 57, Serial No. 6.

Simon, J. A., Keenan, J. M., Pennington, B. F., Taylor, A. K., \& Hagerman, R. J. (2001). Discourse processing in women with fragile $\mathrm{X}$ syndrome: Evidence for a deficit establishing coherence. Cognitive Neuropsychology, 18, 118.

Sobesky, W. E., Pennington, B. F., Porter, D., Hull, C. E., \& Hagerman, R. J. (1994). Emotional and neurocognitive deficits in fragile $\mathrm{X}$. American Journal of Medical Genetics, 51, 378385.

Sobesky, W. E., Porter, D., Pennington, B. F., \& Hagerman, R. J. (1995). Dimensions of shyness in fragile X females. Developmental Brain Dysfunction, 8, 280-292.

Stoneman, Z. (1997). Mental retardation and family adaptation. In W. E. MacLean (Ed.), Ellis' bandbook of mental deficiency, psychological theory and research (pp. 405-437). Mahwah, NJ: Erlbaum.

Volkmar, F. R., Cicchetti, D. V., Dykens, E., Sparrow, S. S., Leckman, J. F., \& Cohen, D. J. (1988). An evaluation of the Autism Behavior Checklist. Journal of Autism and Developmental Disorders, 18, 81-97.

Walker, L. S., Van Slyke, D. A., \& Newbrough, J. R. (1992). Family resources and stress: A comparison of families of children with cystic fibrosis, diabetes, and mental retardation. Journal of Pediatric Psychology, 17, 327-343.

Wikler, L. M. (1986). Periodic stresses of families of older mentally retarded children: An exploratory study. American Journal of Mental Deficiency, 90, 703-706.

York, A., von Fraunhofer, N. T. J., \& Sedgwick, P. (1999). Fragile-X syndrome, Down's syndrome and autism: Awareness and knowledge amongst special educators. Journal of Intellectual Disability Research, 43, 314-324.

Received 8/30/02, accepted 8/20/03.

Editor-in-charge: Frank Floyd

The research reported here was supported by $\mathrm{Na}-$ tional Institutes of Health Grants P01 HD03352, R01 HD24356, R01 AG08768, and T32 HD07489 and by the University of Wisconsin-Madison Graduate School Research Committee and the Merck Scholars II program. The authors are grateful to Loredana Bruno, Stephanie Cawthon, Selma Karadottir, Rene Makuch, Anne O’Brien, Erica Kesin Richmond, Dotty Robison, and Michelle Weissman for their assistance with data collection and management. We are indebted to the families who participated for their support, commitment, and generosity. Requests for reprints should be sent to L. Abbeduto, Waisman Center, University of Wisconsin-Madison, Madison, WI 53705. E-mail: abbeduto@waisman.wisc.edu. 